\title{
Disregard for traffic rules lead to hemi-facial degloving injury with rupture of eye ball
}

\author{
Rachana Gahlawat $^{1 *}$, Sumit Sachdeva ${ }^{2}$, S.V. Singh ${ }^{3}$, Manisha Rathi ${ }^{4}$ \\ ${ }^{1}$ Senior Resident, ${ }^{2}$ Professor, ${ }^{3}$ Senior Professor and Head, ${ }^{4}$ Professor, ${ }^{1-4}$ Regional Institute of Ophthalmology, PGIMS, Rohtak, Haryana, \\ India
}

*Corresponding Author: Rachana Gahlawat

Email: rachanagahlawat9@gmail.com

\begin{abstract}
Degloving injuries are a result of rotational forces that stretch the skin and subcutaneous tissue causing their avulsion from the deeper, less mobile musculoskeletal structures. In this case report, we present the case of a 53 year old male pedestrian who sustained a grievous hemifacial injury with expulsion of eyeball just because of improper implementation and non-following of traffic rules. Most Hemi-facial degloving injuries are reported with intact vision and eyeball. An extensive hemi-facial degloving avulsion injury with rupture of the eyeball encountered by us is extremely rare. To the best of our knowledge, this is the first such reported case in literature. This nature of grievous injury could have been avoided with proper lighting and following of traffic rules.
\end{abstract}

Keywords: Hemi-facial, Degloving, Rupture, Eyeball, Traffic rules.

\section{Introduction}

Degloving injuries are caused by forces stretching the skin and subcutaneous tissue and causing their separation from the deeper musculoskeletal structures. These injuries mainly occur due to industrial and motor vehicle accidents. ${ }^{1}$ The incidence of degloving injury was estimated to be $4 \%$ in study conducted in a trauma centre in Qatar. ${ }^{2}$ In this case report, we present the case of a 53 year old male stroller who sustained a grievous hemi-facial injury with rupture of eyeball just because of improper condition of the road and non- following of traffic rules. To the best of our knowledge, such a case has never been reported before.

\section{Case Report}

A 53 year old male stroller was involved in a road traffic accident. He was crossing an unlit, unpaved peripheral road on the out-skirts of his village when a speeding car turned a corner and hit him. The patient presented to the Emergency and Trauma of PGIMS Rohtak two hours after the accident. His blood pressure at presentation was $122 / 70 \mathrm{mmHg}$ in right arm supine position, heart rate 106 beats per minutes and oxygen saturation was $99 \%$. He was conscious. His Glasgow Coma Scale score was 13 (Eye 4, Verbal 4, Motor $5)$. He sustained an extensive hemi-facial degloving injury of the face which included skin of the forehead, part of the cheek and side of the nose. The inferior eyelid was lying on the side of the cheek and outer shell of eyeball comprising of cornea and sclera were lying outside the eye socket (Fig. 1,2 ). The superior oblique was still attached to sclera. (Fig. 3).

The wound was contaminated with gravel and dirt. Patient was given Tetanus toxoid immunization and was stabilized hemodynamically. The wound was thoroughly cleansed with continuous irrigation. The ruptured eyeball was excised and a thorough debridement was undertaken of all the devitalized tissue. The other eye had 6/6 vision and was within normal limits.

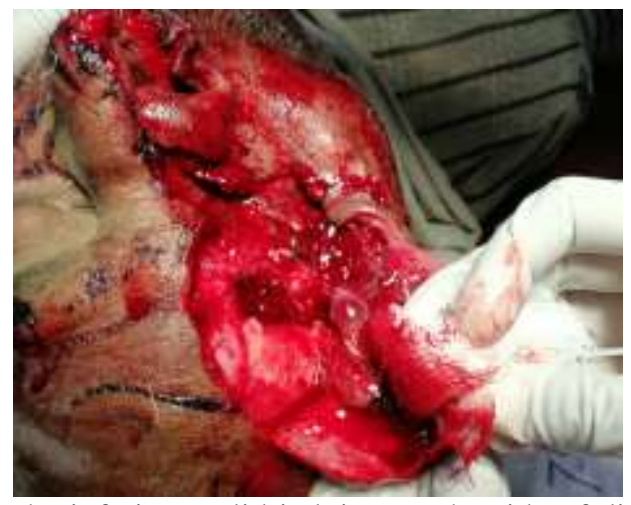

Fig. 1: The inferior eyelid is lying on the side of disfigured cheek.

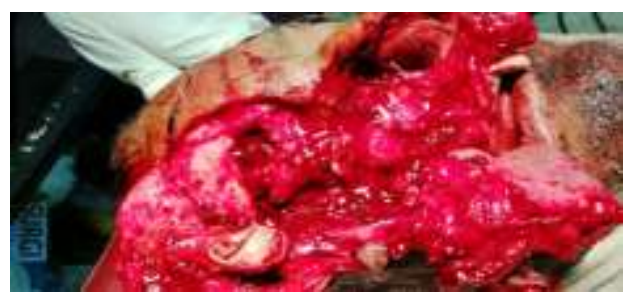

Fig. 2: Cornea and a part of sclera of the rupture eyeball.

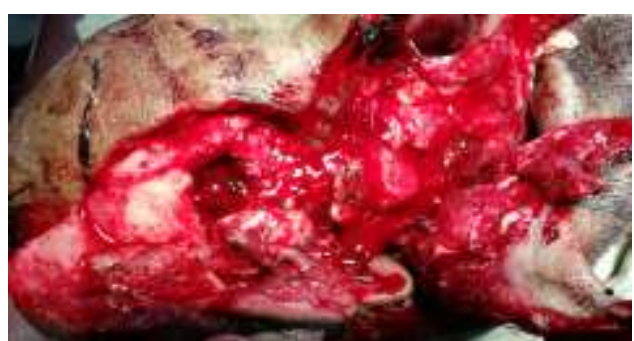

Fig. 3: Supeior oblique is still being seen attached to sclera.

\section{Discussion}

The chief causative factor for a degloving injury is trauma sustained due to machinery and road traffic accidents. ${ }^{1} \mathrm{~A}$ road traffic accident pertains to an accident occurring on a road open to public, involving at least one vehicle, and in 
which at least one person is killed or injured. ${ }^{3}$ In case of a degloving injury, a rotational force pulls the skin and subcutaneous tissue away from the body at a very slow speed. These type of injuries are rare and the mechanism of this injury was narrated by Slack in 1952. Degloving injuries are a type of torsional injury. ${ }^{1}$ These are often associated with nerve, vessel or tendon avulsion. There are reports in literature describing degloving injuries of various areas like the nose and mandible., ${ }^{4,5}$ Bergman et al. reported an orbit and face degloving injury sustained by a 70 -yearold woman caused by her 2 pet dachshunds who chewed her upper face and bilateral periorbital areas. ${ }^{6}$ Avram et al. described two cases of traumatic avulsion of upper lid caused by bites, canine in one and human in another. ${ }^{7}$ Oleteju et al. reported a case of multiple degloving injuries sustained by an elderly man following his fall from a tree. ${ }^{8}$ Degloving injury involving only one half of face are very rare. Panse et al reported a hemi-facial degloving injury but globe and vision was intact in that report. ${ }^{9}$ Ghosh reported another case of hemi-facial degloving with an intact globe. ${ }^{10}$ An extensive hemi-facial degloving avulsion injury with rupture of the eyeball, like the one encountered by us, is extremely rare. To the best of our knowledge, this is the first such reported case in literature. Such a grievous injury could have been avoided, had there been proper lighting on the village road and traffic rules were followed.

Road traffic accidents represent a major chunk of non communicable disease. Road traffic injuries are calculated to be the eighth leading cause of death all over the world with an effect similar to that caused by communicable diseases. It is projected that Road Traffic Accidents will move up to the third position by the year 2020 among leading causes of the global disease burden. There were a total of 4, 64, 910 road accidents reported in India in the calendar year 2017, causing loss of 1,47,913 lives and injuries to 4,70,975 persons, which implies, 1274 accidents and 405 deaths every day or 53 accidents and 17 deaths every hour. ${ }^{11}$ Exposure to adverse traffic environment is high in India because of the unprecedented rate of motorization and growing urbanization fueled by high rate of economic growth. ${ }^{11}$ Accidents carry lofty economic and social damage to the victim, their families and to the country as whole, which are not easy to ascertain. They are the part of the price we pay for technological progress in terms of social, health and economic aspects. India is a signatory to Brasilia Declaration and is dedicated to reduce the number of road accidents and fatalities by 50 per cent by $2020 .{ }^{12}$

Road traffic accidents are multifactorial in nature which involves human, vehicular and environmental factors. But, in our country rather than mechanical, it is the human factors which contribute mainly to road traffic accidents like reckless driving, poor traffic sense, refusal to follow traffic rules, driver fatigue and drunken driving. Vehicular factors include defective vehicle, absence of power-steering or defective brakes. Environmental causes of Road traffic accidents include improper designing of roads, road encroachment, unlit roads, traffic congestion, presence of black spots (Points with 5 or more deaths during the previous year) on the roads, etc. Both human and environmental factors were responsible for the accident in our case.

There is an urgent need to prevent fatal Road traffic accidents in our country. Safety features for vehicles like power-steering, compulsory seat belts, anti-lock braking system etc are a must. Proper designing of roads with pedestrian pavement and functioning traffic lights, rectification of black spots on roads, removal of potholes and unwanted speed brakers should be done. Public should be made aware on road safety through electronic and print media. When planning the design of the roads, road safety should be given utmost importance and road safety audits should be done at regular intervals. To curb the incidence of increasing road traffic accidents, corrective measures need to be undertaken like a greater awareness about traffic rules, controlling drug abuse, implementation of road traffic sense, enforcement of a firm licensing policy and developing a proper well lit road network. These remedies, if strictly implemented, will go a long way in improving the profile of road traffic conditions in India.

\section{Conclusion}

Soft tissue injuries that shave off the superficial tissues from deeper, less mobile tissues are termed as degloving injuries. Patients presenting with degloving injuries need to be stabilized hemodynamically. Assessment of the extent of the injuries should be carried out. Serial wound washouts and debridement are extremely important as wound contamination is a big risk. However, such catastrophic injuries can be avoided by creating awareness about obeying traffic rules. Ideally, traffic rules should be taught in schools. Proper road network with improvement of conditions of roads in remote areas and proper lighting of roads is of utmost importance and facilities for pedestrians needs to be facilitated. Road traffic accidents are usually caused by human errors and are therefore preventable, hence there is an urgent need on the part of everyone to address this epidemic of road traffic accidents.

\section{Conflict of Interest: None.}

\section{References}

1. Slack CC. Friction injuries following road accidents. Br Med J 1952;2:262-4.

2. Hakim S, Ahmed K, El-Menyar A, Jabbour G, Peralta R, Nabir $\mathrm{S}$, et al. Patterns and management of degloving injuries: $\mathrm{A}$ single national level 1 trauma center experience. World $J$ Emerg Surg 2016;11:35.

3. Transport Research Wing, Ministry of Road Transport and Highways. Road Accidents in India 2011. New Delhi: Ministry of Road Transport and Highways, Government of India; 2012.

4. Hallock GG. Nasal degloving injury. Ann Plast Surg 1984;12:537-41.

5. Dula DJ, leicht MJ, Moothart WE. Degloving injury of the mandible. Ann Emergency Med 1984;12:537-41.

6. Bergmann J, Lee K, Klein R, Slonim CB. Upper face and orbit "degloving" dog bite injury. Ophthal Plast Reconstr Surg 2009;25:44-6. 
7. Avram DR, Hurwitz JJ, Kratky V. Dog and human bites of the eyelid repaired with retrieved autogenous tissue. Can $J$ Ophthalmol 1991;26:334-7.

8. Olateju OS, Oginni FO, Fatusi OA, Faponle F, Akinpelu O. Multiple midface degloving injury in an elderly man: challenges and management outcome. J Natl Med Assoc 2007;99:809-13.

9. Panse N, Sahasrabudhe P, Joshi N. Face avulsion and degloving. World J Plast Surg 2014;3:64-7.

10. Ghosh A. Primary One Stage Reconstruction in Complex Facial Avulsion Injury. World J Plast Surg 2017;6:383-6.
11. MoRTH. Road Accidents in India-2017.New Delhi, Ministry of Road Transport and Highways, Transport Research Wing (2018).

12. MoRTH. Road Accidents in India-2015.New Delhi, Ministry of Road Transport and Highways, Transport Research Wing (2016).

How to cite this article: Gahlawat R, Sachdeva S, Singh SV, Rathi M. Disregard for traffic rules lead to hemi-facial degloving injury with rupture of eye ball. Indian J Forensic Community Med 2019;6(2):107-9. 